\title{
7. Bestimmung der specifischen
}

Cohäsion für Kupfer, Eisen, Nickel und Kobalt; von Rudolf Herzfeld.

1.

Quincke $\left.{ }^{1}\right)$ hat aus verschiedenen geschmolzenen Metallen grosse flache Tropfen auf einer horizontalen Unterlage ausgegossen, an den erstarrten Tropfen den verticalen Abstand $\boldsymbol{a}$ zwischen Kuppe und Bauch gemessen und daraus die specifsche Cohäsion für die Schmelztemperatur berechnet. Die specitische Cohäsion des Quecksilbers ist 8,5 qmm. Nach seinen Messungen ist nun die specifische Cohäsion verschiedener Metalle entweder dieselbe wie die des Quecksilbers, oder sie wird aus dieser durch Multiplication mit den ganzen Zahlen 1, 2, $3 \ldots 7$ erhalten. Tropfen von gleichem Durchmesser und gleicher specifischer Cohäsion haben dieselbe Gestalt. Zur ersten Gruppe gehören $\mathrm{Hg}, \mathrm{Pb}, \mathrm{Bi}, \mathrm{Sb}$; zur zweiten $\mathrm{Ag}, \mathrm{Au}, \mathrm{Pt}, \mathrm{Sn}, \mathrm{Cd}$; zur dritten $\mathrm{Zn}, \mathrm{Pd}$; die höchsten Tropfen bildet Na. Quincke hat Kupfer zur zweiten, Eisen zur dritten Gruppe gerechnet, aber es fraglich gelassen, ob nicht beide Metalle einer höheren Gruppe zuzuzählen sind, da die geringste Spur fremder Substanz oder Oxyd an der Oberfläche der Tropfen ihre Höhe verkleinert.

\section{2.}

Zur Herstellung reiner Tropfen aus Kupfer, Eisen, Nickel und Kobalt benutzte ich den electrischen Lichtbogen in folgender Anordnung:

Zwischen einer unteren $15 \mathrm{~mm}$ dicken Retortenkohle und einer oberen $6 \mathrm{~mm}$ dicken französischen Dochtkohle wurde ein Lichtbogen gebildet. Die untere Kohle stand mit dem positiven, die obere mit dem negativen Pole der Accumulatorenbatterie des physikalischen Instituts von 70 Volt Klemmenspannung in Verbindung. Die untere Kohle war mit einem

1) Quincke, Pogg. Ann. 135. p. 523. 1868; 138. p. $141.18{ }_{6} 9$. 
schmalen Rande versehen, und auf den so gebildeten Teller wurden kleine Stücke des betreffenden Metalls gelegt. Die Kohlen wurden in eine Glasröhre eingeschlossen, die unten und oben durch einen Kork luftdicht verschlossen war. Durch jeden Kork führte ausser der Kohle ein dünnes Glasrohr, das zum Hindurchleiten eines Gasstromes diente. Die cobere Kohle war durch ein etwas weiteres Glasrohr geführt und mit einem übergeschohenen Kautschuk darin befestigt; diese Anordnung gestattete bei dichtem Verschluss eine geringe Beweglichkeit nach allen Seiten, sodass der Lichtbogen über den ganzen Teller der Anode geführt werden konnte. Das Metallstück bildete den positiven Pol des Lichtbogens und schmolz bei geeigneter Führung der Kathode zu einem Tropfen zusammen. Dass das Metall zur Anode genommen wurde, hatte den doppelten Vortheil, dass so die durch den Lichtbogen entwickelte Wärme zum grössten Theile dem schmelzenden Metall zu Gute kam, und dass die Verunreinigung des Metalls durch zerstäubte Kohlentheilchen viel geringer wurde, als sie bei umgekehrter Stromrichtung geworden wäre.

Zur Bildung der Kupfertropfen wurde unten ein Strom ron Kohlensäure eingeleitet, der einem Gefäss mit flüssiger Kohlensäure entnommen war. ks wurden so zahlreiche reine Tropfen erhalten. Die anderen untersuchten Metalle zeigten dagegen in einer Kohlensäureatmosphäre chemische Veränderungen, ihre 'Tropfen hatten keinen metallischen Glanz, im Inner'n bildeten sich Blasen. Dies änderte sich auch nicht, als die französische Dochtkohle durch eine reine Homogenkohle der Gebr. Siemens \& Co. in Charlottenburg ersetzt wurde. Erst als statt der Kohlensäure von oben her ein Strom trockenen Wasserstoffs aus einem Kipp'schen Apparate durchgeleitet wurde, erhielt ich bessere Resultate. Beim Schmelzen der Nickel- und Kobaltstücke war besondere Vorsicht nöthig, da die Tropfen, nachdem die ganze Masse flüssig geworden und die Kathode damn schnell entfernt war, sehr oft sich aufblähten und im Innern hohl wurden; ein Zeichen dafür. lass die Gase des Lichtbogens ron dem Metall absorbirt wurlen oder damit chemische Verbindungen eingingen. 
3.

Die erhaltenen Tropfen wurden nun mit Tropfen gleichen Durchmessers von Silber und Palladium verglichen, die im Besitz des Hrn. Prof. Quincke waren. Ausserdem wurden Luftblasen gleichen Durchmessers in Wasser erzeugt, die dieselbe Gestalt wie die Silbertropfen hatten. Die Grösse $a$ wurde mit einem Kathetometermikroskop gemessen. Vier der grössten Kupfertropfen mit einem Durchmesser von $10-11 \mathrm{~mm}$ zeigten $a=3,791 \mathrm{~mm} \pm 0,039 \mathrm{~mm}$; die gleichen Luftblasen hatten höchstens $a=3,31 \mathrm{~mm}$. Auch die Silbertropfen waren sämmtlich niedriger als die Kupfertropfen. Dagegen zeigten sowohl

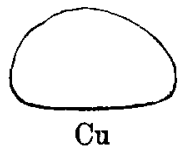

Durchm. $6,48 \mathrm{~mm}$

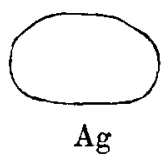

Durchm. $6,50 \mathrm{~mm}$

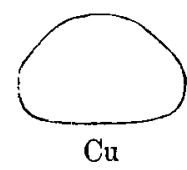

Durchm. 6,68 $\mathrm{mm}$

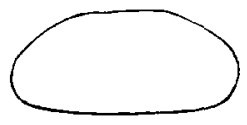

$\mathrm{Cu}$

Durchm. $10,34 \mathrm{~mm}$

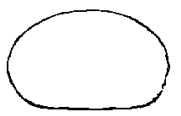

Co

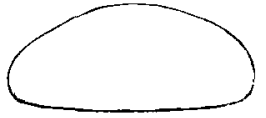

$\mathrm{Cu}$

um $90^{\circ}$ gedreht

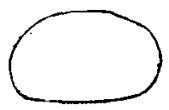

$\mathrm{Ni}$

die Tropfen aus Kupfer, wie die wenigen aus Eisen, Nickel und Kobalt die grösste Aehnlichkeit mit den Palladiumtropfen. An den rollkommensten wurde noch ein Vergleich mit Luftblasen von dem gleichen Durchmesser angestellt. Es ergab sich

\begin{tabular}{lc|ccc}
\hline Metall & Durchmesser & $a$ & $\begin{array}{c}a \\
\text { bei der Luftblase von } \\
\text { gleichem Durchmesser }\end{array}$ \\
\hline \hline Nickel & $5,92 \mathrm{~mm}$ & $2,59 \mathrm{~mm}$ & $2,49 \mathrm{~mm}$ \\
Kobalt & $\mathbf{7 , 5 2}$ & 3,655 & 3,05 \\
Eisen & 5,62 & 3,13 & $\mathbf{2 , 3 9}$
\end{tabular}


Die beigegebenen Figuren zeigen die Gestalt einiger Hacher Tropfen, so wie sie mit der Camera lucida aufgezeichnet wurden. Danach ist die specifische Cohäsion der vier untersuchten Metalle Kupfer, Eisen, Nickel und Kobalt dreimal grösser als die des Quecksilbers, und diese Metalle sind der dritten Gruppe zuzuzählen, ebenso wie Zink und Palladium.

Mir bleibt die angenehme Pticht, Hrn. Geheimrath Prof. Dr. Quincke für das warme Interesse und die liebenswürdige Unterstïtzung, die er diesen Arbeiten angedeihen liess, auch an dieser Stelle meinen herzlichsten Dank auszusprechen.

Heidelberg, im Juni 1897.

Eingegangen 5. August 1897.) 